\title{
Information Dynamics of Undergraduate Students in Gulf Cooperation Council (GCC) Nation
}

\author{
Sajjad ur Rehman1, Ahmad M. AlKandari² \\ ${ }^{1}$ College of Social Sciences, Kuwait University, Kuwait City, Kuwait \\ ${ }^{2}$ Department of Information Studies, College of Social Sciences, Kuwait University, Kuwait City, Kuwait \\ Email:rehman05@gmail.com, amalkandari@hotmail.com
}

How to cite this paper: ur Rehman, S. and Alkandari, A.M. (2020) Information Dynamics of Undergraduate Students in Gulf Cooperation Council (GCC) Nation. Open Access Library Journal, 7: e6212.

https://doi.org/10.4236/oalib.1106212

Received: March 7, 2020

Accepted: March 28, 2020

Published: March 31, 2020

Copyright $\odot 2020$ by author(s) and Open Access Library Inc.

This work is licensed under the Creative Commons Attribution International License (CC BY 4.0).

http://creativecommons.org/licenses/by/4.0/ (c) (i) Open Access

\begin{abstract}
The purpose of this study is to examine the information dynamics of undergraduate students studying in higher education institutions in one of the GCC nations-Kuwait University. This study will help instructors and librarians to understand the challenges that students face when seeking information. This study can help in designing instructional information literacy programs that target student's needs. Also, it can help improve systems and services at educational institutions. A survey was used to gather data for this research by distributing a questionnaire. 355 students participated in the study with a $100 \%$ response rate. It was found that most students use search engines such as Google to search for information. Students also were found that they use the internet as a source for completing assignments. This study showed that social media affects the information dynamics of Kuwait university students. This paper sets a clear observation of student's information dynamics at the GCC nation.
\end{abstract}

\section{Subject Areas}

Information Science, Library, Intelligence and Philology

\section{Keywords}

Information Dynamics, Information Literacy, Library, Social Media

\section{Introduction}

When an individual looks for specific information, one engages in information seeking activities; this is the process of retrieving and using knowledge. When a 
student is able to access a source and obtain the needed document, this is termed as information seeking dynamic. This process will affect how the information users act toward this search dynamic in several ways. Information seeking is a key activity that everyone practices every day. Information users need information to expand their knowledge and pursue their personal and professional pursuits.

Whether or not students use information resources and services is a significant concern for those who manage information systems. Library has long been conceived as one of the possible information systems, used vitally and rigorously. Investigations into library use have long been practiced for examining dynamics users engage in different information processes. Information-seeking behavior varies among students according to their information needs prompting users to bridge peculiar information gaps that exist for each student. Students strive when addressing their information needs, prompted by various personal and academic triggers. Identifying the needed information is the first step involved in retrieving relevant information and engaging in the dynamic of evaluation, use and other applications. All these information activities have certain challenges for users.

It is widely presumed that a large number of undergraduate students do not have enough capabilities for managing these challenging information dynamics. It is significant to examine these baseline competencies that make a critical mass for these information seekers and users who are going through initial stage of higher education.

\section{Problem Statement}

Undergraduate students usually have difficulty in searching, retrieving, and applying the information they need, and most students face diverse problem in managing information dynamics. Student needs are constantly evolving and changing as and when they have to perform different academic tasks and undertakings. There is a need to study information behavior of undergraduate students working in a specific setting. The purpose of this study is to examine the information dynamics of undergraduate students studying in higher education institution in one of the GCC nations-Kuwait University. The term is used synonymously with information behavior or information seeking behavior.

These findings of this investigation may help in discover how information dynamics are managed when these students face any need-academic or personal. There appears to be a dearth of studies on similar topics in the GCC region. Thus this study seems to a need for the context of this region, which is homogenous in linguistic, cultural, economic, and socio-political consideration. The results of this study may develop adequate understanding of the prevalent conditions about information needs, systems and services. Findings of this study may help information providers, library organizations, and other information systems to conceive, process and design appropriate systems and services in 
these universities. It may also provide guidance for creating and managing user empowerment by designing and conducting information literacy programs and facilities.

\section{Research Questions}

This research aims to assess the information dynamics of undergraduate students studying at Kuwait University so as to answer the following research questions:

- Which information dynamics do undergraduate students use with regard to conceiving needs, identifying sources, searching, selecting, accessing, evaluating, using and applying information?

- What difficulties do undergraduate students face in information dynamics?

- What are the management mechanics for information dynamics for the undergraduate students?

\section{Literature Review}

Research about information processes and dynamics of undergraduate students is vital for addressing different questions raised in this study. As was explained earlier, dynamics are diverse, systematic, cyclist, and self-perpetuating in their stance and thrust. Information seeking behavior is a broad term that covers information needs, searching, accessing, retrieval, use and value-added processes for information exploitation and use. This literature review will support this research by bringing relevant studies in the intellectual context of information behavior and processing.

\subsection{Information Behavior}

Information dynamics are innately behavioral. [1] explored the research processing and study behaviors of undergraduate and graduate students. They considered the steps followed in the academic-information-seeking and help-seeking behaviors of students. They used interviews to identify students' differing attitudes toward their academic search processes. Forty percent of students usually asked their instructors for help when working on their assignments. Students most often participated in study groups for specific classes, so as not to miss any work, and to help each other with assignments. Twenty-seven percent of interviewees in the study stated that they preferred seeking help from classmates when they had any questions about their courses. Only one of the fifteen interviewees stated that he first asked a librarian for help during the beginning stages of research. The research team noted that some students were unaware of librarians' roles, and that some students preferred getting help from their peers. The study revealed that most students began their search using library databases, while few began their search using the Internet.

In another related study of first-year students, [2] applied a visual assessment technique to understand and measure the difficulties faced by these students. 
The authors applied the technique at three universities: two in Korea and one in the United States. They found that first-year students frequently experienced difficulties with the transition to academic culture. First-year students typically got introduced to library facilities by librarians, and learned how to access and use the facilities. At one of the universities in Korea, a library instruction class was mandatory for all first-year students. The authors found that first-year students were often self-sufficient. However, first-year students also had difficulties assessing how to use the library space. The researchers concluded that the visual techniques used to assess first-year students' information behavior could provide general information to those concerned with user experience and assessment.

\subsection{Value of Information Skills}

This study has a focus on information dynamics. Naturally, factors involved in the process have a distinct significance. [3] surveyed these factors. They started with identifying variables that might affect the students' behavior. They found that $40 \%$ of students began their search with traditional search engines regardless of the type of project or assignment. Almost $50 \%$ of students used the library catalog and library database as the starting point for their research. Students also visited the library regularly to conduct their library research. The authors found that instructors and library staff have the ability to improve students' performance in research projects. The instructors encouraged students to visit and retrieve information from scholarly sources. Library staff helped students identify and locate appropriate sources. Instructors and library staff positively influenced students' progress.

By investigating undergraduate students' information skills, and the extent to which students learned from library instruction classes, [4] determined whether information seeking skills could be developed in information literacy classes. Students were surveyed, and it was found that 25 out of 98 students had had at least one instruction class. According to the study, more than half of the students had a desire to learn all information literacy capabilities so that they would avoid plagiarism and citation issues. They urged to have OPAC and database searching skills as these appeared to be the weakest skills among students. It was found that attendance of multiple IL sessions made a significant difference.

[5] investigated the IL-related perceptions of information study students using an online survey in which a total of 205 responses were received. Many participants had inadequate searching skills. They found a value in IL programs, followed by social feedback. It was found that emotions, experience, and social factors were significant as the students had perceived. [6] used distance learners from the international programs at the University of London as a case study for understanding their information needs and information behavior. They found a significant connection between distance learners information-seeking activities

and gender of these learners. In general, when reading to enhance their research skills, female's respondents were more engaged than male respondents. The re- 
searchers found that training and instructional sessions on how to search and use information resources were valuable for student learners as a clear pattern was noted in the study.

In a similar study, [7] investigated the information skills of undergraduate students in the school of computing at the University of Utara in Malaysia. A total of 170 students completed a questionnaire. The results showed that students were keen on academic information, followed by substantial content students used in their research. Students preferred to use Google to search for relevant academic information. Another interesting finding was that most students preferred to surf the Internet to retrieve academic information for different assignments, because of the Internet's 24/7 availability. Most students used the Internet to search for information because they encountered problems in finding a required book that was not available in their library.

In the United States, [8] explored how international students used information sources, and the challenges they faced in the process. In an online survey 112 international student's responded. It was found that international students depended primarily on search engines, social media networks, certain printed resources, new friends, and traditional mass media. Another study showed that the use of social networks had increased recently [9].

\subsection{Assessing Information Seeking Behavior}

While various institutions have collected feedback from students after they completed IL classes, this has not provided a consistent guide for instructors to develop, assess, and identify information dynamics. [10] possessed the self-perceived behavior of undergraduate students. The study used a case study for qualitative analysis to examine the role of an embedded information professional. A growing need for assessment was urged due to emerging trends in information systems and dynamics. There existed a strong need to instill life-long learning skills and improve undergraduate students' information dynamics.

Different studies reviewed in this section have highlighted different aspects of information dynamics. Student needs are reflected in their behavior and habits when seeking information. Information professionals are responsible for delivering the necessary instructional materials for enhancing student's self-efficacy in information dynamics. Mandatory sessions must be applied at the beginning of each semester to improve students' skills in information seeking.

\section{Methodology}

This study investigated the information dynamics of undergraduate students at Kuwait University. Survey was used to gather data for this research. A questionnaire was used as a research instrument and was distributed in person to each class.

\subsection{Research Instrument}

As our research instrument, we used a questionnaire. The questionnaire con- 
sisted of 21 questions covering all identified variables. The questionnaire addressed different areas regarding information need conception, source identification, searching, retrieving, accessing, evaluating and using information. It also covered information systems and agencies such as academic libraries in the university system. Using expertise of five faculty members, a pretest was conducted, that facilitated revision and finalization. The instrument had to be translated into, the medium of instruction at Kuwait University. Two faculty members whose first language was Arabic verified that the translated version was free of errors or snags.

\subsection{Data Collection}

As the target population for this study, we used undergraduate students enrolled at Kuwait University in Department of Psychology in the College of Social Sciences for the fall 2018/2019 semester. A cluster sample was used to divide the target population into groups based on ten classes chosen from the course schedule for the department. Classes were numbered in a table from 1 to 109 ; every $11^{\text {th }}$ class was chosen, starting from the $3^{\text {rd }}$ class, until we obtained 10 classes. The sample for this study consisted of the ten systematically selected sections. 355 students participated in the study. The response rate was 100\%.

Instructions and information regarding the questionnaire were delivered to students. The questionnaire was distributed to each class in person at the beginning of class. The participants needed five to ten minutes to answer the questionnaire. The data were collected over a period of two weeks. The data collected from the questionnaire were analyzed using Microsoft Excel. The data were analyzed to determine frequencies, percentages, and mean scores. In the last section of findings, frequencies have been complemented with mean scores and respective standard deviation (sd) scores. The mean score formula used was the sum of Likert scale answers for each question divided by five; the number of answers in the question. The standard deviation formula that was used is:

$$
\sigma=\sqrt{\frac{\sum\left(x_{i}-\mu\right)^{2}}{N}}
$$

$\sigma=$ Population of Standard Deviation.

$N=$ The size of the population.

$X_{i}=$ each value from the population.

$\mu=$ the population mean.

\section{Findings}

A total of 355 students answered the questionnaire that was distributed among ten classes. $43 \%$ of participants were between the ages of $20-21,24 \%$ were 19 years or younger, $21 \%$ were between the ages of $22-23$, and $12 \%$ were over 24 years old. More participants were female than male, because some of the classes in the cluster sample were women-only. Of the participants, $64 \%$ were female, $28 \%$ were male, and $8 \%$ did not specify their gender. 
$68 \%$ of the students who answered the questionnaire are from the College of Social Sciences. Out of the total, $79 \%$ of the students were psychology majors and the rest with different majors in the college.

Table 1 below shows the details of participants for each college.

\subsection{Information Dynamics}

When students were asked about the first place they looked when they needed specific information, $88 \%$ of students responded that they usually used search engines such as Google or Yahoo. Additionally, 5\% of students first used social media applications to find the required information, $5 \%$ used books and encyclopedias, and $1 \%$ used journals and periodicals. $79 \%$ of students usually used different websites as primary resources when they worked on their assignments; $28 \%$ of students used books; $5 \%$ used journals and magazines; $1 \%$ used newspapers; and less than $1 \%$ of students used TV as a source of information, or asked a specialist, or tutor.

When inquired about the possible Web domain, $72 \%$ of participants stated that they used commercial websites (i.e., .com sites) when working on their assignments. Additionally, 24\% used educational websites (.edu sites), and the rest indicated that they use governmental (gov.) or organizational websites (org.).

Of the respondents, $61 \%$ were not familiar with Google scholar, while 39\% were familiar with Google scholar. Figure 1 describes how frequently students use Google scholar.

\subsection{Using the Library as a Resource}

$82 \%$ of participants stated that they had visited the library at the Kuwait University campus, while $18 \%$ of students had not visited the library. Figure 2 describes the frequency of students who visited the library and used it as a resource when seeking information.

Students visit libraries for different purposes. $48 \%$ of students who visited Kuwait University library did so to borrow a book. In contrast, $53 \%$ of students visited the library to study, $11 \%$ to use databases, $9 \%$ to ask questions and use OPAC, $8 \%$ for discussions, $5 \%$ for photocopying, and $7 \%$ for other purposes.

Table 1. Participant affiliation.

\begin{tabular}{ccc}
\hline & $\mathrm{n}=355$ & \\
\hline College of Social Science & 241 & $68 \%$ \\
College of Science & 9 & $3 \%$ \\
College of Allied Health Science & 3 & $1 \%$ \\
College of ART & 18 & $5 \%$ \\
College of Business Adminstration & 28 & $8 \%$ \\
College of Law & 1 & $0 \%$ \\
Not specified & 55 & $15 \%$ \\
\hline
\end{tabular}




\section{How frequently you use google scholar}

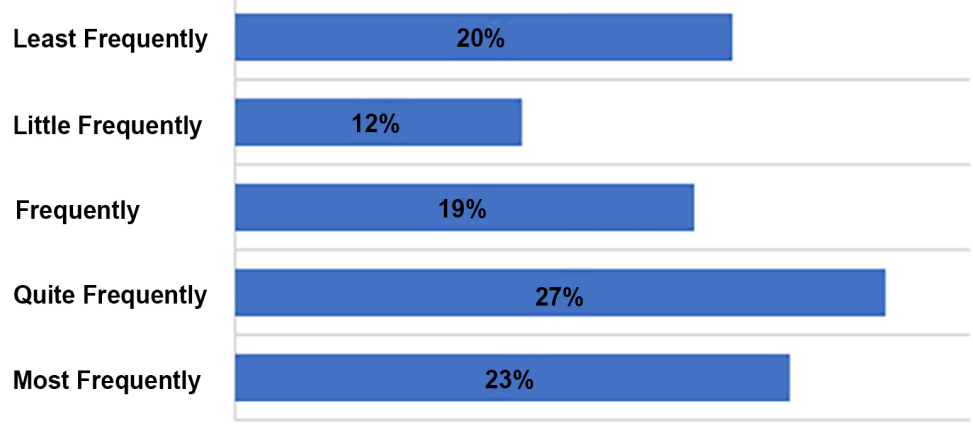

Figure 1. Frequency of use of google scholar.

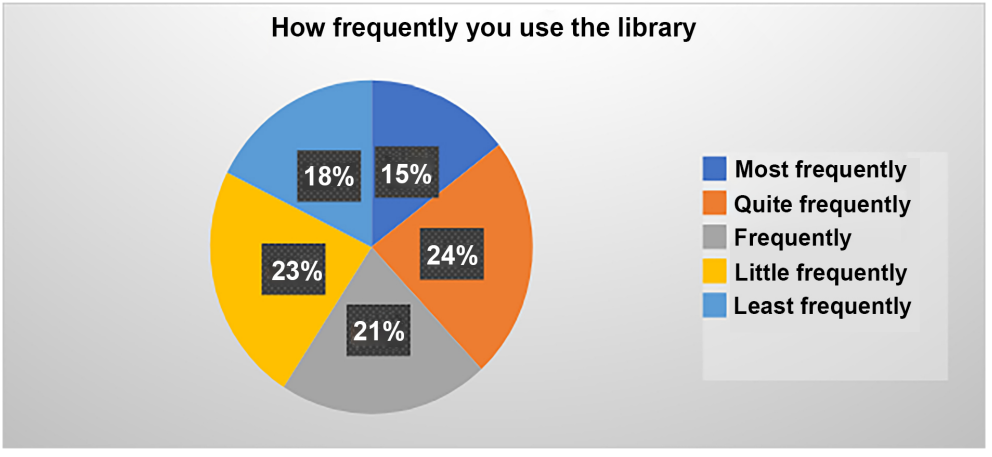

Figure 2. Library usage.

$60 \%$ of students who visited the library at Kuwait University stated that they had not been offered any instructional programs for using library resources. 37\% of students who visited the library indicated that they never sought help from a librarian, while $63 \%$ of student who visited the library had sought help from librarians.

\subsection{Library Satisfaction}

Figure 3 describes the impressions of students regarding the use of the Kuwait University library. It is obvious that the majority of students are satisfied with the Kuwait University library.

Figure 4 describes the satisfaction students feel regarding the information found in the library. It appears that overall students are satisfied with the information available at Kuwait University Library. By comparing to the above finding, $48 \%$ of students visited the library to borrow a book while $11 \%$ to use databases, the finding suffice that the printed collection is an effective source to students.

Figure 5 describes the helpfulness of the information and resources available at Kuwait University library. This figure illustrates that the majority of resource available are helpful to students, from photocopying and computers to printed collection, and databases subscriptions. 


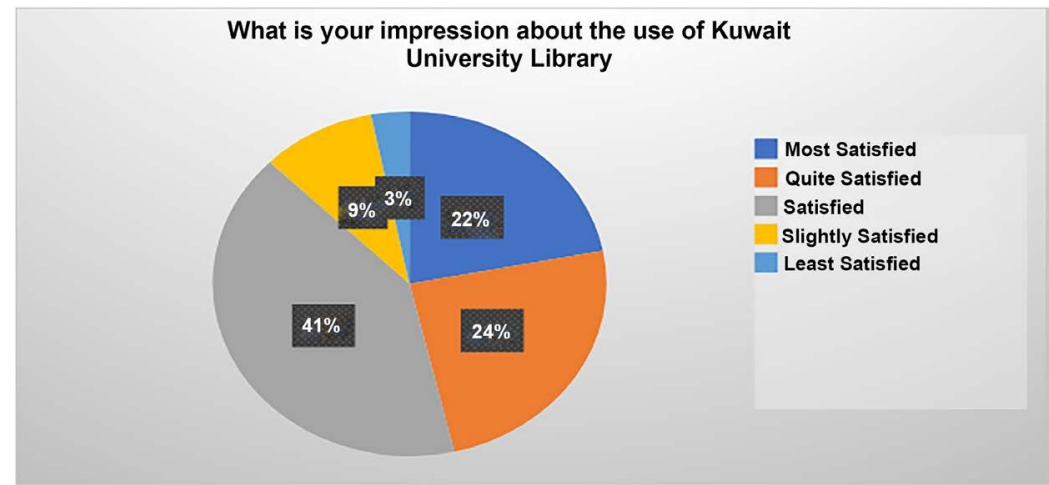

Figure 3. Kuwait University Library usage impression.

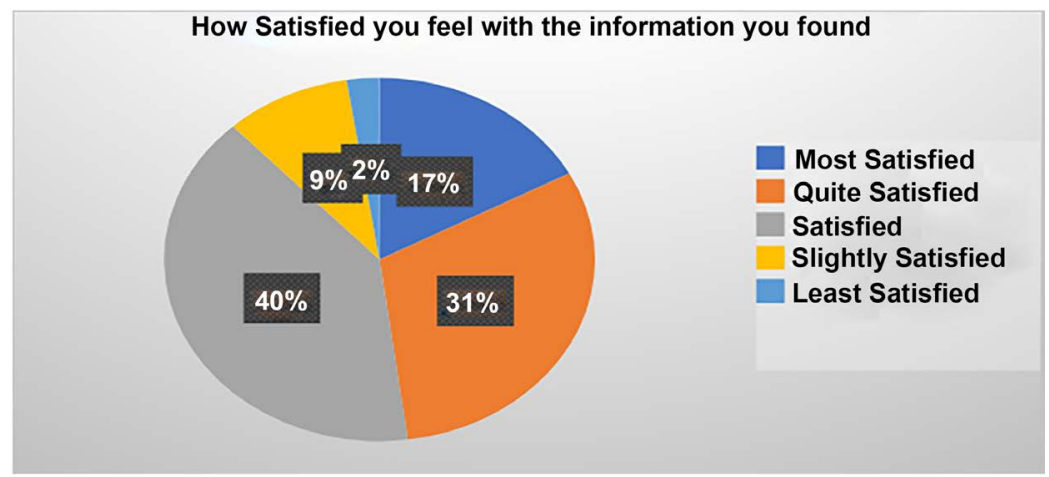

Figure 4. Satisfaction level with information found.

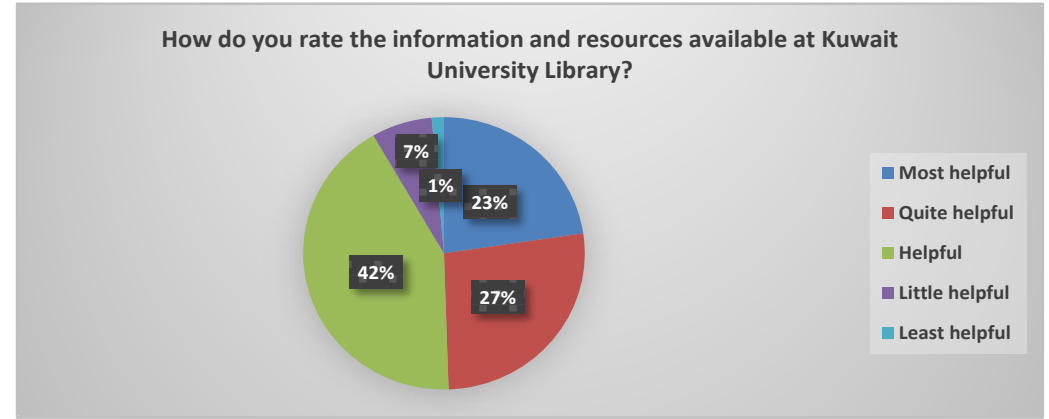

Figure 5. Assessment of Kuwait University Library resources.

\subsection{Student Behavior}

Of the students who participated in the questionnaire, 54\% found that the Internet is a useful source for finding information, 39\% stated that libraries are a useful source, $21 \%$ found faculty and librarians to be valuable sources, $15 \%$ found colleagues helpful, and $11 \%$ found friends to be useful sources. While surfing social media to find information, the majority of students stated that they use twitter, with $62 \%$ using the social media application to find information, 13\% using Instagram, and 29\% using YouTube, 4\% using LinkedIn, and 1\% using Facebook.

Figure 6 below indicates how frequently students use social media applications to find information. 


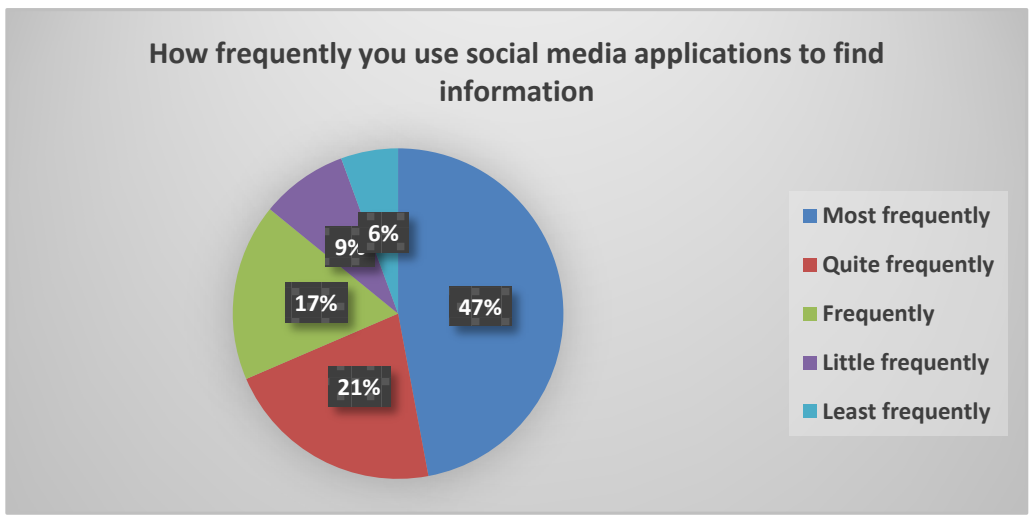

Figure 6. Usage of social media applications as a source of information.

Cell phones and tablets have revolutionized the use of libraries and information seeking behavior. $66 \%$ of students stated that they most frequently use cell phones to find information, $21 \%$ quite frequently, $10 \%$ frequently, $2 \%$ little frequently, and $1 \%$ least frequently. While $63 \%$ of students prefer searching for information virtually or electronically, $15 \%$ search for information at the library and $23 \%$ search for information at home.

\subsection{Mean Scores}

Table 2 gives mean scores and SD scores for all the dimensions that have been analyzed in the earlier section, using figures. Assuming data used is ordinal in nature, these scores also provide further explanation.

With regard to mean scores, four dimensions had mean scores in the close range of 57 - 58. It means that the participants perceived them uniformly. Only one statement dealing with the use of social media received a higher score of 68 . It may be well-inferred that social media are quite popular among the participants of the study as compared to other dimensions of information behavior. It is an important finding that deserves the attention of academics and information professionals.

\section{Discussion and Conclusion}

The findings from the gathered data can simplify the idea of presenting student information dynamics at Kuwait University. Many students at Kuwait University imbed technology in the process of searching for information. Students at $\mathrm{Ku}$ wait University use the Internet regularly to search for information. Most of the students prefer searching web pages first rather than accessing online databases offered by the university. Students also prefer using the internet as an information source rather than visiting the Library. A study by [3] demonstrated that many students place a high value on electronic convenience.

This study showed that social media have an effect on the information dynamics of Kuwait university students. Almost the majority of students at Kuwait University use social media to find information, as shown in Figure 6. 62\% of 
Table 2. Complete coverage \& mean scores.

\begin{tabular}{cccccccccc}
\hline & 5 (MOST) & 4 & 3 & 2 & 1 (LEAST) & $N$ & $S D$ & Mean \\
\hline $\begin{array}{c}\text { How frequently you } \\
\text { use a library }\end{array}$ & 42 & 68 & 61 & 67 & 51 & 289 & 11.12 & 57.8 \\
$\begin{array}{c}\text { What is your impression } \\
\text { about the use of Kuwait } \\
\quad \text { University Libriary }\end{array}$ & 63 & 70 & 118 & 27 & 9 & 287 & 42.22 & 57.4 \\
$\begin{array}{c}\text { How Satisfied you feel with } \\
\text { the information you found }\end{array}$ & 49 & 88 & 115 & 27 & 7 & 286 & 44.13 & 57.2 \\
$\quad \begin{array}{l}\text { How do you rate the } \\
\text { information and resources } \\
\text { available at Kuwait } \\
\quad \text { University Library? }\end{array}$ & 65 & 77 & 121 & 20 & 4 & 287 & 46.74 & 57.4 \\
$\begin{array}{c}\text { How frequently you use } \\
\text { social media applications to } \\
\text { find information? }\end{array}$ & 160 & 73 & 59 & 29 & 19 & 340 & 55.88 & 68 \\
\hline
\end{tabular}

participating students use Twitter as a source of information, $13 \%$ of students use Instagram, and the rest use different social media applications. This distinctly illustrates that student's favor using Twitter to retrieve the information they desire. Interestingly, [11] conducted a study on Kuwait University students' adoption of Twitter as an information source. [11] recommends that librarians and instructors must be part in helping students on how to use Twitter as a source of information, and plan and create beneficial activities regarding the use of Twitter for students. This planning will help students to obtain the best information. [11] also found that Twitter usage among Kuwait University students was driven by perceived enjoyment and social influence factors.

According to our study, $82 \%$ of students stated that they have visited the library at Kuwait University Campus, most of whom visited to study or to borrow a book. Over half of the students stated that they did not receive any instruction on using library resources. [3] stated that it is necessary for instructors to encourage students to use library resources, in order to instill the best behaviors that lead to student success. ([3], p. 429) stated that "Students' informationseeking behavior can be positively influenced by instructors and library staff members".

This study examined Kuwait University students' information seeking behavior. It presented a clear view of how students act in the process of information seeking. This study may guide librarians and instructors at Kuwait University to set clear goals and strategies in designing instructional program in order to strengthen student's abilities. According to [4], many academic libraries are trying to enhance information literacy skills for college students. Librarians must enhance students with different skills by encouraging a mandatory instructional program for freshmen students at the beginning of each semester. This will allow student to gain positive habits in using library resources. 


\section{Conflicts of Interest}

The authors declare no conflicts of interest regarding the publication of this paper.

\section{References}

[1] Thomas, S., Tewell, E. and Willson, G. (2017) Where Students Start and What They Do When They Get Stuck: A Qualitative Inquiry into Academic Information-Seeking and Help-Seeking Practices. The Journal of Academic Librarianship, 43, 224-231. https://doi.org/10.1016/j.acalib.2017.02.016

[2] Pun, R., Hong, Y. and Kim, M. (2017) Telling the First Year Experience: Visual Techniques to Assess First Year Students and Their Information Seeking Behaviours. IFLA WLIC 2017, Wrocław, Poland, 1-6.

[3] Komissarov, S. and Murray, J. (2016) Factors that Influence Undergraduate Information-seeking Behavior and Opportunities for Student Success. The Journal of Academic Librarianship, 42, 423-429. https://doi.org/10.1016/j.acalib.2016.04.007

[4] Tang, Y. and Tseng, H. (2017) Undergraduate Student Information Self-Efficacy and Library Intervention. Library Review, 66, 468-481.

https://doi.org/10.1108/LR-04-2017-0040

[5] Bronstein, J. (2014) The Role of Perceived Self-Efficacy in the Information Seeking Behavior of Library and Information Science Students. The Journal of Academic Librarianship, 40, 101-106. https://doi.org/10.1016/j.acalib.2014.01.010

[6] Tury, S., Robinson, L. and David, B. (2015) The Information Seeking Behaviour of Distance Learners: A Case Study of the University of London International Programmes. The Journal of Academic Librarianship, 41, 312-321. https://doi.org/10.1016/j.acalib.2015.03.008

[7] Nadzir, M.M. (2015) Identifying the Information-Seeking Behaviours among School of Computing Undergraduate Students. Journal of Theoretical and Applied Information Technology, 74, 149-154.

[8] Sin, S.-C.J. (2015) Demographic Differences in International Students' Information Source Uses and Everyday Information Seeking Challenges. The Journal of Academic Librarianship, 41, 466-474. https://doi.org/10.1016/j.acalib.2015.04.003

[9] Sin, S.C., Kim, K.S., Yang, J. and Park, J.A. (2011) International Students' Acculturation Information Seeking: Personality, Information Needs and Uses. In: Proceedings of the Association for Information Science and Technology, ASIST, New Orleans, LA, 1-4. https://doi.org/10.1002/meet.2011.14504801222

[10] Gonzalez, A. (2013) Embedded Academic Librarians Instilling Life-Long Learning Skills: A Proposed Methodology for Assessing Self-Perceived Information-Seeking Behaviors of Undergraduate Students. Qualitative and Quantitative Methods in Libraries, 2, 245-249.

[11] Al-Daihani, S.M. (2016) Students' Adoption of Twitter as an Information Source: An Exploratory Study Using the Technology Acceptance Model. Malaysian Journal of Library \& Information Science, 21, 57-69.

https://doi.org/10.22452/mjlis.vol21no3.4 